\title{
Strategies for interprofessional facilitators and clinical supervisors that may enhance the emotional intelligence of therapy students
}

\section{Abstract}

Emotional intelligence (EI) is a critical skill for occupational therapy, physiotherapy and speech pathology students (therapy students). This paper reports the findings from an analysis of interviews with therapy students $(n=24)$ to determine the aspects of clinical placements that therapy students perceived as influencing the changes in El scores. This paper reports the findings of the qualitative phase of a longitudinal, retrospective mixed methods design. Interviewees were selected using purposive sampling. . Of those interviewed, $95 \%$ agreed that clinical placements had a significant impact on a range of El skills with changes being both positive and negative. Content analysis showed that students perceived their El skills had changed because of the following aspects of clinical placements: student-supervisor interactions, student interactions with patients in emotional distress and being encouraged to reflect and hear feedback on their El skills. To support and enhance student's El skills, interprofessional facilitators and profession-specific supervisors are recommended to utilise the following strategies with interprofessional cohorts. Supervisors and facilitators should be emotionally in-tune with students and trust students to work autonomously with patients experiencing emotional distress, pain and loss, especially those with complex needs. Importantly, interprofessional facilitators and direct supervisors should encourage students to reflect on their EI skills both individually and as a group, Supervisors should frequently evaluate and provide feedback to students on their El skills, at the same time as providing feedback on their practical and clinical reasoning skills. 


\section{Introduction}

Clinical placements for healthcare students are a nexus where theory, assessment, and intervention skills taught in the classroom are practiced and enhanced in authentic settings with real patients under the guidance of experienced practitioners. A primary goal of clinical placements is to prepare healthcare students for unsupervised practice (Hauer et al., 2015), thus clinical placements are an opportunity for students to develop a multitude of skills including interprofessional practice, communication, self-management and an array of intrapersonal and interpersonal skills. Emotional intelligence (EI) is the ability of an individual to understand their own and others emotions and ultimately to make decisions using this emotional data during everyday life (Howe, 2008). Emotional intelligence is reported as pivotal for healthcare professionals to be effective when working with patients as well as working in healthcare teams (Borges et al., 2015; Hurley \& Stansfield, 2012). As Howe (2008, p.10) states, “...the professions that work with people, particularly people in need and distress, should be populated by individuals in goodly possession of emotional intelligence". No previous research was identified that investigated whether clinical placements were perceived by therapy students to influence their El skills, while no literature was identified about how El competencies can be enhanced in students during interprofessional education placements. This paper reports the findings of a content analysis of interviews with occupational therapy, physiotherapy and speech pathology students (therapy students) after the completion of their university coursework and clinical placements. Strategies are described that clinical interprofessional facilitators and profession-specific supervisors can implement to support and enhance the El skills of students during interprofessional education and clinical placements. 


\section{Emotional intelligence}

The importance of El within the structure of human cognitive abilities is becoming increasingly recognised with MacCann, Joseph, Newman Roberts' (2014) indicating that El should be included as a $2^{\text {nd }}$-stratum factor of intelligence of similar standing as visual processing and fluid intelligence. When selecting an El framework on which to base this study, three theoretical constructs were considered - ability based, mixed and trait-based models. Each of these constructs has their own evidence base and measurement tools. The ability-based model, first proposed by Mayer and Salovey in 1990, views emotions as significant sources of information to assist the individual to make sense of and navigate the social environment. The ability-based model purports that individuals vary in their capacity to process information of an emotional nature (Salovey \& Mayer, 1990). The model divides El into four types of abilities: perception of emotion in oneself and in others, assimilation of emotion to facilitate thought, understanding of emotion and managing and regulating emotion in self and others. Mixed models encompass a broader array of concepts than ability based models incorporating "...both abilities and qualities such as personality and motivational traits that assist that person in using El in real life" (Zeidner, Matthews \& Roberts, 2010, p. 26). Bar-on (1997), who first proposed the mixed model, stated “...ultimately, being emotionally and socially intelligent means to effectively manage personal, social and environmental change by realistically and flexibly coping with the immediate situation, solving problems and making decisions. To do this, we need to manage emotions so that they work for us and not against us" (p. 4). Trait-based El is described by Petrides, Vernon, Schermer and Veselka (2011) as an array of emotional self-perceptions, such as adaptability, assertiveness, emotion 
management, relationships and self-motivation, which operationalise the affective aspects of personality. Cherniss, Extein, Goleman \& Weissberg (2006, p. 239) have defended the differing constructs of El stating, “...the generation of several versions of El theory is a sign of vitality in the field, not a weakness. IQ theory... after nearly 100 years of research and theory, there still is not a consensus about what IQ is or the best way to measure it".

The El construct selected for this study, the Model of Emotional-Social Intelligence (Figure 1), is a mixed model, was initially conceptualised by Bar-on (1997) and modified by Multi-Health Systems (2011). This model was selected as it encompasses self-perception, self-expression, interpersonal, decision-making and stress management abilities; skills that are critical for a therapist to use when working with healthcare consumers and in interprofessional teams (Stagnitti, Schoo, \& Welch, 2010). Thus, for the purposes of this study El is defined as a "... set of emotional and social skills that influence the way we perceive and express ourselves, develop and maintain social relationships, cope with challenges and use emotional information in an effective and meaningful way" (Multi-Health Systems, 2011, p.69). The Model of Emotional-Social Intelligence (Figure 1) presents El as a combination of five Composite and 15 Subscale components. A Well-being Indicator is also included - Happiness. 


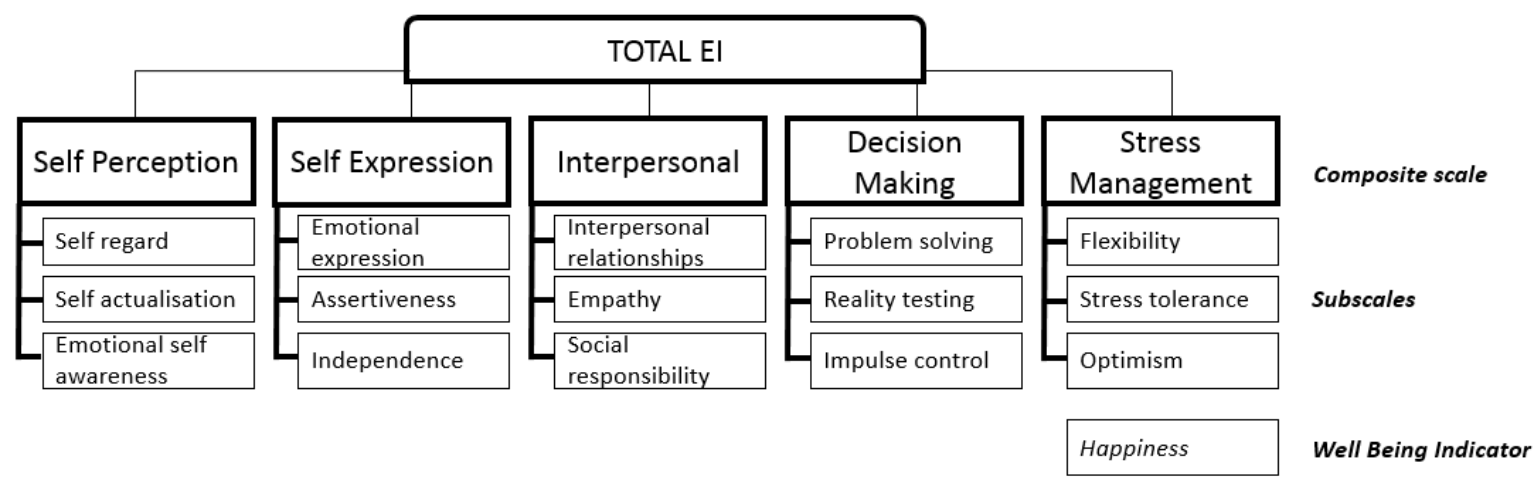

Figure 1: Model of Emotional-Social Intelligence showing the Composite, Subscales and Well-Being Indicator (Multi-Health Systems, 2011)

Barr (1998) suggested eight essential characteristics for collaborative practice. Of the eight characteristics, three require El abilities, namely: working with other professions to effect change and resolve conflict; tolerating differences, misunderstandings and shortcomings in other professions; and entering into interdependent relations with other professions. Furthermore, Banfield and Lackie (2009) identified competencies, performance criteria and behavioural indicators for interprofessional facilitation and collaborative patient-centred practice, many of which also require El competencies. Research has indicated that healthcare professionals with higher El scores have a positive impact on patient satisfaction levels (Azimi, AsgharNejad Farid, Kharazi Fard, \& Khoei, 2010; Weng, Chen, Chen, Lu, \& Hung, 2008), caring behaviours (Corcoran \& Tormey, 2012), reduced job-related stress (Karimi, Leggat, Donohue, Farrell, \& Couper, 2014), higher rates of job satisfaction (Miao, Humphrey, \& Qian, 2016) and improved team performance (Quoidbach \& Hansenne, 2009). As such, healthcare professionals and interprofessional teams proficient in El skills may be more effective in dealing with patients in vulnerable emotional situations and working effectively together.

Emotional intelligence has been shown to be malleable in adults unlike cognitive intelligence (IQ) which is relatively fixed (Stein \& Book, 2011). Emotional intelligence 
tends to increase due to a combination of influences. A Multi-Health Systems (2011) study demonstrated that El increases via natural maturation from the teenage years and into the sixties. These results were reproduced using an Australian sample (Multi-Health Systems, 2012), however, both these studies are cross-sectional and not longitudinal in nature. Zeidner et al. (2010) report that a range of environmental factors such as the affective interactions between family, friends, teachers, coaches and others, may work together to drive the natural maturation of El abilities in the child and teenage years, however, minimal research was identified investigating the factors that influence the development of El in adulthood. Researchers have shown that El in adults can be enhanced by participating in El focussed training and workshops (Boyatzis \& Saatcioglu, 2008; Flowers, Thomas-Squance, BraininRodriguez, \& Yancey, 2014; Zijlmans, Embregts, Gerits, Bosman, \& Derksen, 2015). Another method that may assist El development is workplace learning which has been defined as "...the type of learning that occurs while performing the job itself, such as mentoring, coaching, team learning, increasing job challenge and incidental learning that arises through doing the job" (Clarke, 2006, p.448). Clarke $(2006,2010)$ reports that El skills in healthcare practitioners and teams can be developed via workplace learning.

Clinical placements have been described as the "...most influential learning experience in a student's journey to becoming a competent health professional" (Siggins Miller Consultants, 2012, p.3). Clinical placements are obligatory for therapy students in Australia and generally occur in all years of undergraduate therapy programs, although longer full-time placements that are the focus of this study tend to occur towards the end of the course (Stagnitti et al., 2010). The attributes required 
to facilitate interprofessional education placements for healthcare professionals are well documented (Banfield \& Lackie, 2009). As the Australian Government Department of Health (2015, p. 12) state, the supervisor requires “...high quality level of interpersonal engagement (requiring) higher order interpersonal skills involving feedback, active listening, remedial discussion and positive reinforcement". The role of the interprofessional facilitator (defined for this paper as the healthcare professional whose role is to coordinate the interprofessional education clinical placement) is focussed on managing the learning environment, facilitating interprofessional learning, role-modelling professional behaviours and assessment of learning (Emerson, 2004; Marshall \& Gordon, 2010). Whereas the practical and clinical reasoning skills are generally considered the domain of the professionspecific supervisor (Stagnitti, Schoo, \& Welch, 2010). Gillieatt et al.'s (2014) study of an interprofessional training program for clinical supervisors used Proctor's model for student supervision as the underpinning conceptual basis of the course. Proctor's model (1987) proposes three main functions of the clinical supervisor: (1) administrative, (2) formative or educative, and importantly for this study, (3) a restorative or supportive role. This supportive or restorative role would require EI skills to be demonstrated by the interprofessional facilitator and profession-specific supervisors. There is no current literature on the impact of the supervisor and clinical placement environment on the El abilities of students. Nor is there literaturesuggesting strategies that interprofessional facilitators could use to enhance the emotional intelligence of individual students or the interprofessional cohort of students.

Only a few studies have tracked the El of healthcare students during their university programs. Gribble, Parsons and Ladyshewsky (2017) reported that occupational 
therapy, speech pathology and physiotherapy students' El scores tended to fluctuate during final year clinical placements with assertiveness, problem solving, impulse control, self-actualisation, and stress tolerance competencies decreasing in $33 \%$ or more of the students over a 6 month period. Benson, Martin, Ploeg and Wessell (2012) examined changes in El of 52 nursing students over a four-year period, finding that emotional adaptability, situational coping, and flexibility changed significantly. On the other hand, Lewis (2011) tracked 87 physiotherapy students over three years with no significant change in El scores but did report that students who failed their licensing examination tended to have lower El scores. Similarly, Larin et al. (2011) also found no significant change in El amongst 73 nursing and 60 physiotherapy students from the beginning of their course to after their first clinical placement. Although Stratton, Saunders and Ellam (2008) did not track El specifically, their study of 64 medical students found that the students' ability to effectively manage emotions fluctuated across the undergraduate course. No studies were identified that tracked changes in El scores in students who completed interprofessional education placements.

Given, that clinical placements are a form of workplace learning where healthcare students are expected to practice a variety of skills including El, investigating the impact of clinical placements on the development of El in therapy students has merit. The majority of research into clinical placements for therapy students appears to focus on the role of the supervisor and the learning environment on the student's performance or satisfaction. Research reports that the relationship between the student and supervisor has a significant influence on student's satisfaction with a clinical placement (Chan, 2004; Gillieatt, Martin, Marchant, Fielding, \& Duncanson, 
2014; Proctor, 2001). Pront, Gillham and Shuwirth (2016) found the themes that underpinned quality clinical experiences and supervision were when the supervisor was able to 'partner', 'nurture', 'engage' and 'facilitate meaning' with the student. On the other hand, Siggins Miller Consultants (2012) reported that poor quality placements were characterised by occupational stress and a culture of incivility towards the student.

During clinical placements, students learn to work with healthcare consumers experiencing an array of conditions including pain, emotional distress and loss. Students also work closely with clinical supervisors who may have a positive or negative influence on student's performance during clinical placements. Thus investigating if, and how, El may change during clinical placements from the student's perspective is warranted. As such, the following questions were formulated: Do therapy students perceive that changes in their El skills are due to their clinical placements? If so, what aspects of the clinical placement do therapy students perceive as influencing changes in their El skills?

\section{Methods}

This paper reports the findings of the qualitative phase of a longitudinal, retrospective mixed methods design (Plano Clark et al., 2015). A mixed methods design was selected. Qualitative data were collected to understand changes in the participants' quantitative data (Plano Clark et al., 2015). The quantitative stage (Phase 1) of this study collected El scores and demographic data via online questionnaires at three time-points over the final 16-months of the therapy students' university program. The qualitative stage (Phase 2) used semi-structured interviews 
to investigate the perceived impact that clinical placements had on El scores. The study was approved by the university's Human Research Ethics Committee.

\section{Participants}

Differing sampling techniques were used for the two phases. Phase 1 participants were recruited from a convenience sample of third-year undergraduate occupational therapy, physiotherapy, and speech pathology students ( $n \sim 650)$ enrolled at four Australian universities. These three therapy professions were chosen because they frequently work together with similar patients in interprofessional teams. Forty percent of the sample $(n=261)$ completed the first questionnaire, with only 109 students participating at all three time-points. Reasons for the non-responders were not sought, but by the third questionnaire, students had completed their university course and may have disengaged from using the university email system.

Interviewees for Phase 2, were recruited using purposive sampling. The inclusion criteria to be invited to interview were (a) the participant had completed the three questionnaires and (b) analysis of participant El results showed a positive or negative change of eight points or more in four or more El scores. A change of eight points was selected, as the mean change in scores for all participants from T1 to T3 was 4.16 (SD 2.1). To answer the research questions, it was critical to interview students who had registered relatively large positive and negative changes in El scores. Participants meeting the inclusion criteria $(n=71)$ were emailed. Ultimately, 24 participants agreed to be interviewed despite multiple email requests. Reasons for a relatively low response rate may have been that participants had completed their university course and disengaged from the university email system. Interviews were conducted by the researcher either face-to-face $(n=18)$ or over the phone 
$(n=6)$. After the interview, participants were provided AUD $\$ 20$ to reimburse the participant's time and to cover costs such as traveling, parking at the university and phone calls. The reimbursement was approved by university's Human Research and Ethics Committee and adhered to guidelines stipulated in the National Statement of Ethical Conduct in Human Research (2015). Because of the time needed to analyse the Phase 1 data and the Christmas and summer holiday period in Australia, the final interviews were completed 16 weeks after the final questionnaire was completed.

\section{Data collection}

Measurement of emotional intelligence. The Model of Emotional-Social Intelligence measures El with the Emotional Quotient Inventory, now in its second iteration known as the Emotional Quotient Inventory 2.0 or EQ-i².0 (Bar-On, 1997, 2006; MultiHealth Systems, 2011), a self-report tool measuring emotional and socially intelligent skills. The EQ-i ${ }^{2.0}$ is a 133 item self-report tool. Participants answer questions such as: "I'm in touch with others feelings" and "I feel overwhelmed when I need to make a decision" using a five-point scale from 'Never/Rarely' through to 'Always/Almost Always'. Raw scores are converted to a standard score for each of the $22 \mathrm{EI}$ domains. For all 22 domains, scores above 110 are considered high, with scores between 90 and 110 considered normal and scores below 90 considered low. The highest score possible on each domain is 135 with the lowest score being zero. Testretest reliability of the EQ-i. ${ }^{2.0}$ for Total El was high $(r=0.92)$ for participants who were tested two to four weeks apart but lower $(r=0.81)$ when measured eight weeks apart. Internal consistency demonstrated Cronbach's alpha scores of 0.97 for Total $\mathrm{El}$, composite scales ranged from 0.88 to 0.93 with 0.77 to 0.93 for the 15 subscales (Multi-Health Systems, 2011). The EQ-i ${ }^{2.0}$ also calculates an Inconsistency Index, 
Positive Impression and Negative Impression score, which resulted in 11 participants being excluded from interviews.

Semi-structured interview process. The same researcher conducted all 24 interviews. Interviews ranged from 30 to 75 minutes. Participants signed a consent form prior to the interview. Interviewees were read the Multi-Health Systems (2011) definition of El and then the interviewer provided a description of the Model of Emotional-Social Intelligence. Interviewees were provided with a printout of their 22 El scores at the three time-points. Interviewees who were contacted by telephone were emailed their El scores beforehand. For each interviewee, the researcher had highlighted four to six El scores that had increased or decreased by eight points or more. For each El score, the interviewee was provided with the definition for that EI domain (from Multi-Health Systems, 2011). The interviewee was then asked, "Do you agree that this El score has increased (or decreased) over the last 16 months?" This question was included to clarify if the interviewee perceived that the specific El ability had changed, and if so, in the direction indicated. If the interviewee responded positively, the researcher then asked, "Do you think the change was due to your clinical placements, personal factors or a combination of the clinical placements and personal factors?" If the interviewee agreed the change in El score was due to clinical placements, they were asked, "What occurred during your clinical placements that may have influenced this change in this El score?"

\section{Data Analysis}

Content analysis of the interviews followed an inductive category development approach as suggested by Hsieh and Shannon (2005). Interviews were transcribed 
verbatim by a professional transcription service. The researcher (NCG) checked the transcripts against the recording for accuracy. Using NVivo10, each transcription

was read (by NCG) to gain a sense of the whole before deriving codes. Open coding occurred by the grouping similar codes into sub-themes and labeling them. Finally, the sub-themes were congregated to create the main themes. A summative approach (Hsieh \& Shannon, 2005) was then used by counting the frequency of themes and quotations used to create each theme and sub-theme from the interview transcriptions. According to Plano Clark et al. (2015), a longitudinal, retrospective mixed methods study uses qualitative data collected at the final data collection point to examine respondent's recollections of what was measured quantitatively. Thus, the number of students reporting each theme provides an indication of the strength of each theme. To add rigour and credibility, an occupational therapist (KE), who has experience supervising therapy students, scrutinised the categorisations by being randomly assigned $25 \%$ of the interview transcriptions to review the tentative categorisations. The researcher (NCG) and occupational therapist (KE) held ongoing discussions to fine-tune the categorisations. To increase internal validity, member checking was conducted via phone with six (25\%) of the original interviewees. Two questions were posed: "Do you recognise the categorisations from your clinical placements?" and; "Do you find the descriptions illustrative of the categorisations?" All interviewees accepted the categorisations.

\section{Results}

Of the 24 interviewees who participated in this study, 18 were female and six male, 12 were occupational therapy students, six speech pathology and six from physiotherapy. Interviewees were 22 to 26 years, except one who was 49 years. The 
students had completed between three to six clinical placements in metropolitan, rural and international locations over the 16-month period of the study with a mean total length of all clinical placements being 115 days $(S D=11)$. Models of supervision during the placements included one supervisor with one student, multiple students working with one supervisor, one student being supervised by multiple part-time supervisors and self-directed placements with minimal direct supervision. Eleven percent of the students reported that they participated in a placement designated specifically as an interprofessional placement. For example, one university runs an aged care residential placement employing a full-time interprofessional facilitator onsite to oversee occupational therapy, physiotherapy, nursing, social work and speech pathology students' interprofessional education placement. These students also have access to a profession-specific supervisor. In some cases in this paper, the term 'supervisor' is used to indicate the interprofessional facilitator and professionspecific supervisor.

Each interviewee was asked questions about four to six of their El scores resulting in $126 \mathrm{El}$ score changes being discussed across all interviews. Most interviewees agreed $(95 \% ; n=120)$ that the increase or decrease in El score was due to their clinical placements, with only $5 \%(n=6)$ perceiving that the El change was due to personal factors only. Table 1 details the frequency each El score was discussed during the interviews, whether scores increased or decreased and the range of the change in scores for each El domain. 
Table 1: El scores discussed during interviews, ordered by frequency discussed

\begin{tabular}{|c|c|c|c|c|}
\hline & $\begin{array}{l}\text { Frequency } \\
\text { discussed }\end{array}$ & $\begin{array}{c}\text { Score } \\
\text { increased } \\
>8 \text { points }\end{array}$ & $\begin{array}{c}\text { Score } \\
\text { decreased } \\
>8 \text { points }\end{array}$ & $\begin{array}{l}\text { Max. and min. } \\
\text { individual change in El } \\
\text { scores between } \mathrm{T} 1-\mathrm{T} 3\end{array}$ \\
\hline Empathy & 12 & 7 & 5 & +19 to -19 \\
\hline $\begin{array}{l}\text { Emotional } \\
\text { expression }\end{array}$ & 10 & 5 & 5 & +21 to -21 \\
\hline Independence & 10 & 8 & 2 & +19 to -19 \\
\hline Flexibility & 10 & 9 & 1 & +24 to -8 \\
\hline Assertiveness & 9 & 3 & 6 & +7 to -26 \\
\hline Reality testing & 9 & 7 & 2 & +14 to -18 \\
\hline Stress management & 9 & 6 & 3 & +20 to -13 \\
\hline Optimism & 8 & 7 & 1 & +16 to -22 \\
\hline Self-actualisation & 7 & 4 & 3 & +24 to -19 \\
\hline Self-regard & 6 & 4 & 2 & +13 to -15 \\
\hline $\begin{array}{l}\text { Emotional self- } \\
\text { awareness }\end{array}$ & 6 & 3 & 3 & +17 to -15 \\
\hline Stress tolerance & 5 & 3 & 2 & +22 to -10 \\
\hline Self-expression & 4 & 2 & 2 & +14 to -19 \\
\hline Decision-making ${ }^{\star}$ & 4 & 4 & 0 & +15 (no decline) \\
\hline Impulse control & 4 & 2 & 2 & +24 to -18 \\
\hline Self-perception & 3 & 2 & 1 & +24 to -16 \\
\hline Social responsibility & 3 & 2 & 1 & +14 to -11 \\
\hline Problem solving & 3 & 2 & 1 & +12 to -9 \\
\hline Interpersonal & 2 & 2 & 0 & +17 (no decline) \\
\hline $\begin{array}{l}\text { Interpersonal } \\
\text { relationships }\end{array}$ & 2 & 1 & 1 & +14 to -17 \\
\hline Happiness & & & & \\
\hline TOTALS & 126 & 81 (64\%) & 45 (36\%) & \\
\hline
\end{tabular}

\section{Content analysis}

Content analysis identified two key stages where El was impacted during the clinical placement. Initially, during the first few days of full-time placements, students experienced a lack of confidence and feeling overwhelmed which induced a decline in some El skills. Secondly, over the remainder of the placements, El skills tended to move in positive or negative directions. Themes and sub-themes are presented using quotations from interviewees. Interviewees are identified by a code (e.g. 06-FOT) that indicates the interviewee was number 06 , who was a female, occupational therapy student. 


\section{Initial stages of clinical placements}

The findings indicate that the first week or so of a placement appears to be a critical stage where student's El abilities are challenged. During the initial stages of clinical placements, students $(n=17 ; 71 \%)$ reported feeling under-confident, even fearful, when confronted by patients experiencing emotional distress, pain or loss for the first time:

"You start (placements) with so much fear in your head. I was quite unsure of myself." (23-F-PT)

"I had difficulty whenever the patient was having a tough time or crying. I'm always hesitant as to how to handle that. And I think I'm just not really old enough or have had the experience to deal with situations like that." (06-FOT)

Students reported that starting placements generated a dose of reality on how crude their El skills actually were, with some reporting an initial reduction in El skills. This was especially evident with assertiveness where $67 \%(n=9)$ of those interviewed reported a decline in ability:

"When you hit those full-time fieldwork pracs you actually get dropped down a notch and go, phew...my empathy is not as good as it could be, or I could be more assertive, or my self-regard is actually dropping off here. It's a lot harder to be empathetic than I thought." (04-F-ST)

"I think prac is really good at poking holes in your understanding of yourself. The expectations of what I thought might be required during prac were vastly different to what I actually needed in the workforce." (02-F-OT)

\section{During clinical placements}

The second stage of El change occurred during the fieldwork placement where the three main themes of clinical placements that the students perceived as influencing their El skills were: supervisor interactions, patient interactions, and reflection and feedback on El skills. Within each of these, sub-themes were identified which 
influenced $\mathrm{El}$ in an upward or downward direction depending on the nature of the interaction. Positive interactions led to growth in El scores whereas negative interactions caused a decline in El scores. Ultimately, sub-themes were included if $50 \%$ or more of the interviewees reported the facet of the clinical placement to be influential in the increase or decrease of El scores. Table 2 presents the themes and sub-themes during clinical placements that were perceived to influence El skills.

Table 2: themes and sub-themes of clinical placements that influence El skills, including frequency and number of quotes from the interview transcriptions

\begin{tabular}{llcc} 
Themes & Sub-theme & $\begin{array}{c}\text { Interviewees } \\
\text { discussing this } \\
\text { theme }(\mathbf{n} / \mathbf{2 4})\end{array}$ & $\begin{array}{c}\text { Number of } \\
\text { quotes related } \\
\text { to this theme }\end{array}$ \\
\hline $\begin{array}{l}\text { Patient } \\
\text { interactions }\end{array}$ & Confronting scenarios & $18(75 \%)$ & 171 \\
& Confidence increasing & $18(75 \%)$ & 142 \\
\hline & Emotionally engaged & $22(92 \%)$ & 26 \\
Supervisor & Trusts the student & $19(79 \%)$ & 122 \\
interactions & Role modelling El skills & $13(54 \%)$ & 51 \\
& Negative influences & $22(92 \%)$ & 76 \\
& Feedback on specific El skills & $16(67 \%)$ & 74 \\
\hline $\begin{array}{l}\text { Reflection } \\
\text { and feedback }\end{array}$ & Reflective practice & $19(79 \%)$ & 46 \\
\hline
\end{tabular}

\section{Patient Interactions}

Full-time clinical placements are the first time that many therapy students assume responsibility for a caseload where they are required to interact daily with patients experiencing an array of emotional scenarios. Two sub-themes were identified: confronting scenarios and confidence increasing.

Confronting scenarios. Students $(n=18,75 \%)$ recounted numerous stories where they were confronted by scenarios they had never dealt with previously. Students reported the opportunity to deal with patients in emotionally vulnerable situations on a daily basis was a positive influence on El skills. Due to lack of experience, students 
initially had difficulty knowing how to react and what to do when confronted with patients in distress:

"Just being exposed to clients like that definitely, helps. Because in my day-today life I don't really experience people crying or telling me the worst thing that's ever happened to them all the time. So when you are exposed to that situation more clinically, I grew." (11-F-OT)

“...I was working with a patient newly diagnosed with cancer. She was already palliative, so she was experiencing a complete change ... she had a young daughter...I felt like I was lacking empathy because I had these jobs to do. I needed to find out about her home and that sort of thing. I just felt that I wasn't appropriate, and I couldn't show enough empathy. I just felt as though I shouldn't have been there." (24-F-OT)

Confidence increasing. After the initial anxieties, a positive outcome of working alongside patients in complex emotional states was that students $(n=18,75 \%)$ perceived an increased confidence in their ability to manage these scenarios using a range of El skills:

"...I think the change comes with more confidence. When you start to feel like you are in the "groove" of it a bit more, and you get the hang of things. I think it's easier to feel more assertive when you feel like you know what you are doing." 15-F-SP

“...(during prac) I learnt on a deep level what empathy actually means. My confidence to be empathetic grew when I realised it was not about me overlaying my own experience, but being open to what they were bringing and experiencing and hearing what they were going through. You can read all you like about empathy, but being empathetic is completely different." 01-F-OT

\section{Supervisor Interactions}

The critical role of the interprofessional facilitator and profession-specific supervisor are highlighted by interviewees reporting that the quality of the student-supervisor interactions was perceived as a critical component influencing the change in El scores, with a range of positive and negative influences being identified. The 
positive influences included the supervisor being emotionally in-tune and trusting the student as well as role modeling El skills.

Supervisor emotionally in-tune with the student. Students $(n=22,92 \%)$ suggested that supervisors who were genuinely concerned and mindful of when the student needed emotional support assisted the student to increase their confidence in a range of El skills, as indicated by these quotations:

“...I was crapping myself about running an anxiety/depression group. But I was quietly confident because I had a really good supervisor sitting next to me. I knew he was just pushing me... he realised where my own anxiety would stop me from pushing myself. He gave me enough anxiety to perform, but not too much where I started fearing him. He made me feel safe to explore." (07-M-OT)

"My supervisors were fantastic. They'd say 'It's okay. Take a minute' when I needed it. Just having that kind of reassurance to be allowed to step out for a couple of minutes and just calm myself down. It was nice to be 'heard'. The good supervisors understand you and they let you grow." (23-F-PT)

Students $(n=14,58 \%)$ reported that supervisors who understood that they were a student, novice therapist with minimal experience allowed El skills to flourish more than supervisors who expected the student to be performing beyond a graduate level, exemplified by these quotations:

"...they were patient with the fact that I was still a student, and didn't have a lot of experience. I had decent theoretical knowledge base, but my clinical skills were not up to standard or well developed. She knew the areas and types of practice that would help and benefit me most." (09-M-PT)

"..I had this great supervisor. She realised I was a bit nervous on my first day. She asked me questions and she would initiate conversations with me and that made me more comfortable to speak my mind. I just felt like I couldn't talk to this other supervisor." (07-M-OT) 
Supervisor trusts the student. Student's $(n=19,79 \%)$ frequently discussed that El skills, such as independence and self-regard, improved when a supervisor trusted and valued the student. For example, by allowing them to practice independently with patients even when they were struggling, which allowed the students to be true to themselves. Positive outcomes are illustrated by these quotations:

"My supervisor had the faith and belief in me to do it by myself which was really good. So that gave you the confidence to work with patients independently. During my first placement, I wasn't given that autonomy." (03M-PT)

"I think I wasn't so stressed because the supervisor showed that she was confident in my abilities, and I felt comfortable - confident in my abilities. So once she did that, I could relax and be myself." (22-F-SP)

Conversely, this student highlighted the negative impact supervisors can have when they show a lack of trust by taking over a patient treatment session from the student:

"I had other supervisors that talk over you and just take over when I thought I was doing things perfectly. The supervisor would go "Oh, you are not going say anything. I will just do it"." (23-F-PT)

Role modeling of El Skills. Students $(n=13,54 \%)$ appeared to flourish when they were able to observe their interprofessional facilitator or supervisor using El skills with patients in emotionally vulnerable states or dealing with difficult patients, as illustrated by these quotations:

"... on my first day, a patient turned round and said 'fuck off'. My supervisor was so calm and held her hand, talked calmly and spent time just being with her. Later we talked about it. I know that watching my supervisor helped me grow." (01-F-OT)

"... l'd see my supervisor do something and my mind would be blown and that would make me sort of reset my view of myself and where I am at." (02-F-OT)

Negative Influences of Supervisors. The majority of students $(n=22,92 \%)$ recalled times when supervisors had a negative impact on their El abilities. These students 
reported they tended to shut down emotionally when supervisors instigated an overt power differential or hierarchy between the student and the supervisor or gave overly critical feedback:

"...the way it felt to me is like the supervisor's 'God'. You've got to try and impress God. She just had that attitude that you've got to do everything you can to please them. I like being on the same footing." (07-M-OT)

"Whenever she'd ask me a question and l'd say something, my answer was always wrong. She made me feel bad about myself. And so I didn't really want to say anything. I shutdown. I had to." (08-F-SP)

This student highlighted how even negative body language, can result in a student shutting down emotionally and cognitively:

"I'm applying the monofilament to this guy's hand (to measure a patient's sensitivity to touch in the hand), and I saw out of the corner of my eye, the supervisor dropping her head. And I immediately felt intimidated. I just fell apart. I couldn't think what to do next." (07-M-OT)

Similarly, when these students perceived that the supervisory style induced a sense of fear they reported waning El skills:

"Like one of those supervisors who feels that students develop better when you put fear in them. When you put fear in them it means that they'll perform because they need anxiety to perform." (07-M-OT)

"With this supervisor I felt put back - actually, belittled. My supervisor had overwhelmed me and it really "squished me". So, even though I had some improvement in some of my individual clients, the whole experience "dumbed" my self-regard. My own success with those clients wasn't big enough to overcome the supervisor's impact on me." (22-F-SP)

\section{Reflection and Feedback}

Students perceived that El was enhanced when reflection and feedback focussed on the student's El skills, as well as assessments, interventions, practical skills and verbal and written communication. 
Feedback on specific El skills. These students ( $n=16,67 \%)$ reported a growth in skills when supervisors promoted regular, clear and honest feedback on specific EI abilities alongside practical skills:

"(The supervisor) pulled me up for being not assertive enough. They would challenge me to do better. They gave me a few phrases to use next time which were good ideas." (22-F-SP)

"When you're working with a supervisor who's watching you every day and giving you feedback on things you're doing right, things you're doing wrong. You get very good at noticing more things about yourself. And how you're feeling about things." (05-M-OT)

"... (great supervisors) give me feedback that's really in tune with what I think. It's not just generic. It's really specific to you. It's direct." (15-F-PT)

However, supervisors who provided mostly negative feedback tended to hinder the student's El skills, such as this student:

"...there are great supervisors who are firm with you, who are pushing you, who are challenging you, but it's done in a safe environment. Whereas when you are in the environment of fear, where there is a hierarchy. That hinders your learning, your engagement and your use of your emotional intelligence skills." (07-M-OT)

Reflective practice. Students ( $n=19,79 \%)$ reported using an array of techniques to reflect on their practice skills, as well as their El abilities including journaling, formal and informal sessions with supervisors and debriefing with other students on placement:

"My paediatric placement was a really positive experience. My supervisors were constantly prompting me to reflect after sessions. They were really good at tapping into how I was feeling. And how I was I was dealing with kids with disabilities." (06-F-OT)

"On my international prac I was at my most emotionally expressive because that was a more challenging prac in terms of emotions, and what you're 
confronted with. Being with lots of other prac students all the time, living together, is very challenging, and so you do have to be able to express how you're feeling and what you're thinking about." (11-M-OT)

"I love looking back at my journal from my (international placement). I can really see where I was at. I can see how I've grown. I can see how good and bad I was. I can go back and re-reflect and relearn. I often wrote 'this happened' and 'the nurses did this' and 'I was really offended'. I go back a few days later and think 'hang on a tick, what I can learn from this." (01-F-OT)

\section{Discussion}

This study has ascertained that $95 \%$ of the therapy students who were interviewed perceived that clinical placements had an impact - both positive and negative - on their El skills. Interviewees frequently described supervisors and interprofessional facilitators as skilful mentors and educators who set up a safe learning environment that resulted in student's reporting improving El skills. However, students also described supervisory styles that hindered the development, and in some cases, crushed the student's perceived El skills. The role of creating a positive learning environment where students can observe, practice and gain feedback on their EI skills should fall equally on both the interprofessional facilitator and professionspecific supervisor. Supervisors need to be particularly cognisant of the fluctuating nature of student's El abilities in the first week of so of placements where students are reporting feeling vulnerable and under-confident. Facilitating interprofessional education and clinical placements for healthcare students is challenging and demanding for the interprofessional facilitator and profession-specific supervisor (Evans, Shaw, Ward, \& Hayley, 2016). No previous studies have identified strategies that interprofessional supervisors and profession-specific supervisors can implement to support and possibly enhance the El competencies of students. 
The key influences on El skills during clinical placements were the studentsupervisor interactions, students working with patients experiencing emotional distress, pain or loss, and students receiving feedback and reflecting on their EI skills. These themes parallel findings from other studies (Black et al., 2010; Pront et al., 2016) however; none of these studies explored the impact of clinical placement environment on El skills and therapy students' capacity to cope with emotional demands during placements. Black and colleagues' (2010) study followed physiotherapists during their first year of practice positing that 'interactions with patients/caregivers', 'interactions with co-workers/mentors' and 'reflection, informal and formal continuing education', work together to increase their confidence and professional identity. Similarly, our study showed that therapy students undertaking clinical placements in a positive learning environment initially reported self-doubt about their ability to deal and cope with emotional situations. However, over time and with more exposure to patients and complex emotional scenarios, their belief in their El skills increased. Alternately, interviewees who reported placements with a poor supervisory style or learning environment detailed a decline in El skills resulting in them tending to shut down emotionally and return to a state of internal self-doubt. High quality facilitation of interprofessional placements is vital for the student cohort to experience a meaningful and worthwhile placement (Nicol \& Forman, 2014) while researchers have frequently reported the quality of the student-supervisor relationship as an influential factor in effective supervision (Hall, McFarlane, \& Mulholland, 2012; Tomas, Giberson, Black, \& Pinkerton, 2008). Similar to our study, Pront et al. (2016) found the key attributes of quality clinical placements occurred when the supervisor was able to 'partner', 'nurture', 'engage' and 'facilitate meaning' with the student. A key learning for interprofessional facilitators and supervisors is 
that they need to demonstrate and role-model El skills within their role. Our study has shown that supervisors, who use these strategies, tend to have a positive influence on the El skills of therapy students.

The students' perception that supervisors can have a negative effect on student's EI is an important finding of our study. These findings are important to interprofessional facilitators and supervisors because if the student-supervisor relationship is poor, a student might reduce their emotional expression and lose confidence in verbalising their thoughts and feelings. Ultimately, a supervisor might see this emotional shutdown as a student whose overall performance and clinical reasoning are declining, and possibly on a pathway to failing the clinical placement. These findings align with Kanno and Koeske (2010) who reported that students who perceived their supervisor to be inadequate recounted emotional exhaustion, burnout and diminished confidence in clinical reasoning.

Although the findings that positive and negative supervisory styles impact the performance of students during clinical placements is not new, our study is unique in showing the impact on perceived El abilities. Our findings should be noteworthy for interprofessional facilitators, supervisors, and university academics. Clinical supervisors are recommended to utilise the following strategies with students, which may result in an improvement in El skills.

Traditionally, interprofessional facilitators and profession-specific supervisors have encouraged students to reflect on their practical skills, clinical reasoning, ethical and professional behaviours (Mann, Gordon, \& MacLeod, 2009; Tan, Ladyshewsky, \& Gardner, 2010). Previous research has shown that reflection between therapy 
students and practitioners can enhance clinical reasoning and allowed students to recognise the value and importance of reflective practice (Williams, Wessel, Gemus, \& Foster, 2002). Our study shows that students, who reflect on their El skills, perceive growth in these abilities, with the supervisor being the preferred source of reflection. Students also reported using a written journal and conversing with other students as beneficial sources of reflection. Thus, interprofessional facilitators and profession-specific supervisors are encouraged to reflect with students, not only practical skills and clinical reasoning, but also on the emotional milieu of workplace, patients' emotional states and El skills.

Many interviewees advocated that interprofessional facilitators and professionspecific supervisors allow students to work autonomously with patients with complex emotional issues (when considered safe by the supervisor) earlier in clinical placements. Students reported wanting to be trusted by their supervisor. Enabling them to work autonomously with complex emotional scenarios displays to the student that they are a valued member of the team. These suggested strategies are underpinned by Bandura's (1994) sources of self-efficacy development, particularly mastery and vicarious experiences. Bandura considers mastery experience to be the most influential source of self-efficacy. Students in our study confirmed this by highlighting the importance of being trusted to work with patients in emotionally vulnerable situations and subsequently experiencing success. Bandura (1994, p.3) states that "...success build a robust belief in one's personal efficacy". Thus, supervisors who tend to shield students from complex emotional or distressed patients may be detrimental to students El development. Vicarious experiences require the student to observe others in action (Bandura, 1994) and thus the role- 
modelling by supervisors on how to react and behave in emotional scenarios is critical to students enhancing their El skills.

The majority of students interviewed discussed the importance of a supervisor who is emotionally engaged with the student. Interprofessional facilitators and professionspecific supervisors are encouraged to check the emotional status of individual students, as well as the interprofessional student cohort. Supervisors can maintain an emotional connection with the students by asking them questions about their emotional state. Supervisors need to avoid inducing a sense of fear in the student by being aware of the power differential inherent in student-supervisor relationship and treating the student as a peer as much as possible. These suggestions align with Fredrickson's (2001) broaden-and-build theory, whereby immersion in an environment with more positive emotions can enable individuals' to build their own personal resources, including social and psychological skills, thus eliciting a wider array of thoughts and actions within the person. Fredrickson's presents evidence that negative emotions narrow the thoughts and actions that come to mind. Yet this must be tempered when students on clinical placements are under-performing and critical and constructive feedback is required, that may elicit negative emotions. No matter how a student is performing during placements, clinical supervisors are encouraged to be in-tune with student emotionally and understand how they deal with the varying emotional states at play during a clinical placement.

In relation to study limitations, the EQ-i ${ }^{2.0}$ used to measure El is a self-report instrument that ultimately measures participant's perception of their El skills, not actual ability. Future studies might use ability-based measurement tools to track EI 
changes. The study did not focus specifically on students who had completed interprofessional education placements; however, $11 \%$ of students reported that had completed such a placement. Future studies could focus solely on the interprofessional facilitator. The inclusion criteria for interviews required participants who reported large changes in personal El scores. Future studies could include students who had minimal changes, to see if and how clinical placements influenced their perceived El scores. Interviewees were only from one state of Australia and it would be beneficial to replicate this study in other geographical contexts. Only undergraduate students were included in the study in an attempt to homogenise the sample, however, future studies could include post-graduate students who tend to be older and possibly more emotionally mature. The timing of the final questionnaire lead to a lower than expected response rate. This reduced the number of participants that met the inclusion criteria for interviews. As a result, those students that volunteered to be interviewed may have an element of selection bias. The response rate and non-response bias may also be potential limitations. The timing of the final questionnaire also delayed the interviews, so that some interviews were completed 16 weeks after the final clinical placement. This may have influenced the student's recall of placement experiences.

\section{Concluding comments}

Emotional intelligence is seen as a critical skill for interprofessional teams and therapists that should be fostered before and during clinical placements by interprofessional facilitators and supervisors. The findings of this study are important to university educators who prepare clinical supervisors in preparation for hosting students during clinical placements. Clinical supervisor training should highlight the 
positive and negative impact that supervisory styles might have on the El skills of therapy students. Supervision by interprofessional facilitators and supervisors that supports, rather than crushes, El development may result in the maturation of therapy students El skills, which may result in stronger clinical placement performance and ultimately, superior graduates entering the workforce.

\section{Acknowledgements}

We would like to acknowledge Torbjorn Falkmer for ongoing advice and support; Kiah Evans for assistance with data analysis; and Greg Lynne and Tim Parkin for assistance with interview transcription as well as the many students who participated.

\section{Declaration of interest}

The authors report no conflicts of interest. The authors alone are responsible for the content and writing of this article. No funding sources were used for this study.

\section{References}

Azimi, S., AsgharNejad Farid, A. A., Kharazi Fard, M. J., \& Khoei, N. (2010). Emotional intelligence of dental students and patient satisfaction. European Journal of Dental Education, 14(3), 129-32. http://doi.org/10.1111/j.16000579.2009.00596.x

Australian Government - Department of Health. (2015). The role of the clinical supervisor in interprofessional pre-registration student clinical education - the unmet educational need in university wide health studies clinical practice. Retrieved from http://www.heti.nsw.gov.au

Bandura, A. (1994). Self-efficacy. In V. S. Ramachaudran (Ed.), Encyclopedia of human behavior: Volume 4 (pp. 71-81). New York: Academic Press.

Banfield, V., \& Lackie, K. (2009). Performance-based competencies for culturally responsive interprofessional collaborative practice. Journal of Interprofessional Care, 23(6), 611-620. http://doi.org/10.3109/13561820902921654

Bar-On, R. (1997). Emotional quotient inventory. Toronto: Multi-Health Systems, Inc.

Bar-On, R. (2006). The Bar-On model of emotional-social intelligence (ESI). Psicothema, 18(Suppl S), 13-25. 
Barr, H. (1998). Competent to collaborate: Towards a competency-based model for interprofessional education. Journal of Interprofessional Care, 12(2), 181-187. http://doi.org/10.3109/13561829809014104

Benson, G., Martin, L., Ploeg, J., \& Wessel, J. (2012). Longitudinal study of emotional intelligence, leadership, and caring in undergraduate nursing students. The Journal of Nursing Education, 51(2), 95-101. http://doi.org/10.3928/01484834-20120113-01

Black, L. L., Jensen, G. M., Mostrom, E., Perkins, J., Ritzline, P. D., Hayward, L., \& Blackmer, B. (2010). The first year of practice: an investigation of the professional learning and development of promising novice physical therapists. Physical Therapy, 90(12), 1758-73. http://doi.org/10.2522/ptj.20100078

Borges, N. J., Thompson, B. M., Roman, B. J., Townsend, M. H., Carchedi, L. R., Cluver, J. S., ... Levine, R. E. (2015). Team Emotional Intelligence, Team Interactions, and Gender in Medical Students During a Psychiatry Clerkship. Academic Psychiatry, 4-6. http://doi.org/10.1007/s40596-015-0282-4

Boyatzis, R. E., \& Saatcioglu, A. (2008). A 20-year view of trying to develop emotional, social and cognitive intelligence competencies in graduate management education. Journal of Management Development, 27(1), 92-108. http://doi.org/10.1108/02621710810840785

Carmichael, M. A., Bridge, P., \& Harriman, A. (2016). Emotional intelligence development in radiation therapy students: A longitudinal study. Journal of Radiotherapy in Practice, 15(1), 45-53. http://doi.org/10.1017/S1460396915000461

Chan, D. S. (2004). The relationship between student learning outcomes from their clinical placement and their perceptions of the social climate of the clinical learning environment. Contemporary Nurse: A Journal for the Australian Nursing Profession, 17(1-2), 149-158. http://doi.org/10.5172/conu.17.1-2.149

Cherniss, C., Extein, M., Goleman, D., \& Weissberg, P. R. (2006). Emotional intelligence: What does the research really indicate? Educational Psychologist, 41, 239-245. http://doi.org/10.1207/s15326985ep4104_4

Clarke, N. (2006). Developing emotional intelligence through workplace learning: Findings from a case study in healthcare. Human Resource Development International, 9(4), 447-465. http://doi.org/10.1080/13678860601032585

Clarke, N. (2010). Emotional intelligence and learning in teams. Journal of Workplace Learning, 22(3), 125-145. http://doi.org/10.1108/13665621011028594

Corcoran, R. P., \& Tormey, R. (2012). Assessing emotional intelligence and its impact in caring professions: The value of a mixed-methods approach in emotional intelligence work with teachers. In A. Di Fabio (Ed.), Emotional intelligence - new perspectives and applications. InTech. http://doi.org/10.5772/1188 
Emerson, T. (2004). Preparing placement supervisors for primary care: an interprofessional perspective from the UK. Journal of Interprofessional Care, 18(2), 165-182. http://doi.org/10.1080/13561820410001686927

Evans, S., Shaw, N., Ward, C., \& Hayley, A. (2016). "Refreshed... reinforced...reflective": A qualitative exploration of interprofessional education facilitators' own interprofessional learning and collaborative practice. Journal of Interprofessional Care, 30(6), 702-709. http://doi.org/10.1080/13561820.2016.1223025

Flowers, L. K., Thomas-Squance, R., Brainin-Rodriguez, J. E., \& Yancey, A. K. (2014). Interprofessional social and emotional intelligence skills training: study findings and key lessons. Journal of Interprofessional Care, 28(2), 157-9. http://doi.org/10.3109/13561820.2013.847407

Fredrickson, B. L. (2001). The role of positive emotions in positive psychology: the broaden-and-build theory of positive emotions. American Psychologist, 56(3), 218-226. http://doi.org/10.1037/0003-066x.56.3.218

Gillieatt, S., Martin, R., Marchant, T., Fielding, A., \& Duncanson, K. (2014). Evaluation of an inter-professional training program for student clinical supervision in Australia. Human Resources for Health, 12(1), 60. http://doi.org/10.1186/1478-4491-12-60

Gribble, N. C., Ladyshewsky, R. K., \& Parsons, R. (2017). Fluctuations in the emotional intelligence of therapy students during clinical placements: Implication for educators, supervisors, and students. Journal of Interprofessional Care, 31(1), 8-17. http://doi.org/10.1080/13561820.2016.1244175

Hauer, K. E., Oza, S. K., Kogan, J. R., Stankiewicz, C. A., Stenfors-Hayes, T., Cate, O. Ten, ... O'Sullivan, P. S. (2015). How clinical supervisors develop trust in their trainees: a qualitative study. Medical Education, 49(8), 783-795. http://doi.org/10.1111/medu.12745

Howe, D. (2008). The emotionally intelligent social worker. New York: Palgrave MacMillan.

Hsieh, H., \& Shannon, S. E. (2005). Three approaches to qualitative content analysis. Qualitative Health Research, 15(9), 1277-1288.

http://doi.org/10.1177/1049732305276687

Hurley, J., \& Stansfield, C. (2012). Why emotional intelligence matters in health and social care. In J. Hurley \& P. Linsley (Eds.), Emotional Intelligence in Health and Social Care: a Guide for Improving Human Relationships (pp. 17-28). London, UK: Radcliffe Publishing.

Kanno, H., \& Koeske, G. F. (2010). MSW students' satisfaction with their field placements: The role of preparedness and supervision quality. Journal of Social Work Education, 46(1), 23-38. http://doi.org/10.5175/JSWE.2010.200800066

Karimi, L., Leggat, S. G., Donohue, L., Farrell, G., \& Couper, G. E. (2014). Emotional rescue: The role of emotional intelligence and emotional labour on well-being 
and job-stress among community nurses. Journal of Advanced Nursing, 70(1), 176-186. http://doi.org/10.1111/jan.12185

Larin, H. M., Benson, G., Martin, L., Wessel, J., Williams, R., \& Ploeg, J. (2011). Examining change in emotional-social intelligence, caring, and leadership in health professions students. Journal of Allied Health, 40(2), 96-102. Retrieved from http://www.ncbi.nlm.nih.gov/pubmed/21695370

Lewis, E. (2011). Longitudinal assessment of emotional intelligence in Doctor of Physical Therapy students. The Internet Journal of Allied Health Sciences and Practice, 9(2). Retrieved from http://ijahsp.nova.edu/articles/Vol8Num4/Lewis.htm

MacCann, C., Joseph, D. L., Newman, D. A., \& Roberts, R. D. (2014). Emotional intelligence is a second-stratum factor of intelligence: Evidence from hierarchical and bifactor models. Emotion, 14(2), 358-74. http://doi.org/10.1037/a0034755

Mann, K., Gordon, J., \& MacLeod, A. (2009). Reflection and reflective practice in health professions education: a systematic review. Advances in Health Science Education, 14, 595-621. http://doi.org/10.1007/s10459-007-9090-2

Marshall, M., \& Gordon, F. (2010). Exploring the role of the interprofessional mentor. Journal of Interprofessional Care, 24(4), 362-374. http://doi.org/10.3109/13561820903275001

Miao, C., Humphrey, R. H., \& Qian, S. (2016). A meta-analysis of emotional intelligence and work attitudes. Journal of Occupational and Organizational Psychology, 1-26. http://doi.org/10.1111/joop.12167

Multi-Health Systems. (2011). EQ-i 2.0 Emotional Quotient Inventory 2.0 - user's handbook. North Tonawanda, NY, USA: Multi-Health Systems.

Multi-Health Systems. (2012). EQi-2.0 Australian norms. Retrieved November 12, 2012, from http://ei.mhs.com

Nicol, P. W., \& Forman, D. (2014). Attributes of effective placements for interprofessional placemnet facilitation. Journal of Research in Interprofessional Practice and Education, 4(2), 1-11. Retrieved from http://link.library.curtin.edu.au/p?cur_digitool_dc225195

Petrides, K. V, Vernon, P. A., Schermer, J. A., \& Veselka, L. (2011). Trait emotional intelligence and the dark triad traits of personality. Twin Research and Human Genetics : The Official Journal of the International Society for Twin Studies, 14(1), 35-41. http://doi.org/10.1375/twin.14.1.35

Plano Clark, V. L., Anderson, N., Wertz, J. A., Zhou, Y., Schumacher, K., \& Miaskowski, C. (2015). Conceptualizing longitudinal mixed methods designs: A methodological review of health sciences research. Journal of Mixed Methods Research, 9(4), 297-319. http://doi.org/10.1177/1558689814543563

Proctor, B. (1987). Supervision: a co-operative exercise in accountability. In M. Marken \& M. Payne (Eds.), Ensuring and Enabling: Supervision in Practice (pp. 
1-87). Leicester, UK: National Youth Bureau and the Council for Education and Training in Youth and Community Work.

Pront, L., Gillham, D., \& Schuwirth, L. W. T. (2016). Competencies to enable learning-focused clinical supervision: A thematic analysis of the literature. Medical Education, 50(4), 485-495. http://doi.org/10.1111/medu.12854

Quoidbach, J., \& Hansenne, M. (2009). The impact of trait emotional intelligence on nursing team performance and cohesiveness. Journal of Professional Nursing, 25(1), 23-9. http://doi.org/10.1016/j.profnurs.2007.12.002

Rodger, S., Chien, C. W., Turpin, M., Copley, J., Coleman, A., Brown, T., \& Caine, A. M. (2013). Establishing the validity and reliability of the Student Practice Evaluation Form-Revised (SPEF-R) in occupational therapy practice education: A rasch analysis. Evaluation \& the Health Professions, 36(1), 44-66. http://doi.org/10.1177/0163278713511456

Salovey, P., \& Mayer, J. D. (1990). Emotional intelligence. Imagination, Cognition and Personality, 9(3), 185-212. http://doi.org/10.1016/S0191-8869(98)00001-4

Siggins Miller Consultants. (2012). Promoting quality in clinical placements : Literature review and national stakeholder consultation. Retrieved August 10, 2015, from https://www.hwa.gov.au/

Stagnitti, K., Schoo, D., \& Welch, D. (2010). Clinical and fieldwork placements in the health professions. Melbourne: Oxford University Press.

Stein, S. J., \& Book, H. . (2011). The EQ Edge: Emotional Intelligence and Your Success (3rd ed.). Mississauga, Canada: Jossey-Bass.

Stratton, T. D., Saunders, J. A., \& Elam, C. L. (2008). Changes in medical students' emotional intelligence: An exploratory study. Teaching and Learning in Medicine, 20(3), 279-284. http://doi.org/10.1080/10401330802199625

Tan, S. M., Ladyshewsky, R. K., \& Gardner, P. (2010). Using blogging to promote clinical reasoning and metacognition in undergraduate physiotherapy fieldwork programs. Australasian Journal of Educational Technology, 26(3), 355-368.

The National Health and Medical Research Council. (2015). National Statement on Ethical Conduct National Statement on Ethical Conduct in Human Research 2007 (Updated May 2015). Canberra: Australian Research Council and Australian Vice-Chancellors' Committee. Retrieved from https://www.nhmrc.gov.au/

Tomas, R., Giberson, T. R., Black, B., \& Pinkerton, E. (2008). The impact of studentclinical instructor fit and student-organization fit on physical therapist clinical education experience outcomes. Journal of Physical Therapy Education, 22(1), 59.

Weng, H.-C., Chen, H.-C., Chen, H.-J., Lu, K., \& Hung, S.-Y. (2008). Doctors' emotional intelligence and the patient-doctor relationship. Medical Education, 42(7), 703-11. http://doi.org/10.1111/j.1365-2923.2008.03039.x 
Williams, R. M., Wessel, J., Gemus, M., \& Foster, S. E. (2002). Journal writing to promote reflection by physical therapy students during clinical placements.

Physiotherapy Theory and Practice, 18(1), 5-15.

http://doi.org/http://dx.doi.org/10.1080/095939802753570657

Zeidner, M., Matthews, G., \& Roberts, R. D. (2010). What we know about emotional intelligence: How it affects learning, work, relationships, and our mental health. London, England: The MIT Press.

Zijlmans, L. J. M., Embregts, P. J. C. M., Gerits, L., Bosman, A. M. T., \& Derksen, J. J. L. (2015). The effectiveness of staff training focused on increasing emotional intelligence and improving interaction between support staff and clients. Journal of Intellectual Disability Research, 59(7), 599-612.

http://doi.org/10.1111/jir.12164 